\title{
Prison tobacco control policies and deaths from smoking in United States prisons: population based retrospective analysis
}

\begin{abstract}
Objective To determine the mortality attributable to smoking and years of potential life lost from smoking among people in prison and whether bans on smoking in prison are associated with reductions in smoking related deaths.

Design Analysis of cross sectional survey data with the smoking attributable mortality, morbidity, and economic costs system; population based time series analysis.

Setting All state prisons in the United States.

Main outcome measures Prevalence of smoking from cross sectional survey of inmates in state correctional facilities. Data on state prison tobacco policies from web based searches of state policies and legislation. Deaths and causes of death in US state prisons from the deaths in custody reporting program of the Bureau of Justice Statistics for 2001-11. Smoking attributable mortality and years of potential life lost was assessed from the smoking attributable mortality, morbidity, and economic costs system of the Centers for Disease Control and Prevention. Multivariate Poisson models quantified the association between bans and smoking related cancer, cardiovascular and pulmonary deaths.

Results The most common causes of deaths related to smoking among people in prison were lung cancer, ischemic heart disease, other heart disease, cerebrovascular disease, and chronic airways obstruction. The age adjusted smoking attributable mortality and years of potential life lost rates were 360 and 5149 per 100000 , respectively; these figures are higher than rates in the general US population (248 and 3501,
\end{abstract}

respectively). The number of states with any smoking ban increased from 25 in 2001 to 48 by 2011. In prisons the mortality rate from smoking related causes was lower during years with a ban than during years without a ban (110.4/100 $000 v 128.9 / 100000)$. Prisons that implemented smoking bans had a $9 \%$ reduction (adjusted incidence rate ratio 0.91 , $95 \%$ confidence interval 0.88 to 0.95 ) in smoking related deaths. Bans in place for longer than nine years were associated with reductions in cancer mortality (adjusted incidence rate ratio $0.81,95 \%$ confidence interval 0.74 to 0.90 )

Conclusions Smoking contributes to substantial mortality in prison, and prison tobacco control policies are associated with reduced mortality. These findings suggest that smoking bans have health benefits for people in prison, despite the limits they impose on individual autonomy and the risks of relapse after release.

\section{Introduction}

Smoking tobacco significantly contributes to premature death and accounts for about six million deaths worldwide each year, ${ }^{1}$ including deaths from lung cancer, ischemic heart disease, chronic obstructive pulmonary disease, and cerebrovascular disease. In the United States at year end 2011, there were 1.4 million people in state prisons. ${ }^{2}$ The prison population includes many smokers ${ }^{3-6}$ with estimates of prevalence of smoking ranging from $50 \%$ to $83 \%{ }^{7-9}$ substantially higher than the general population outside prison. ${ }^{9}$ Among people formerly in prison, smoking is an important contributor to mortality. ${ }^{10}{ }^{11}$ Little is known, however, about the cumulative effects of smoking, 
including past and current exposure, among individuals in prisons. We therefore first determined the smoking attributable mortality and years of potential life lost from smoking in US prisons.

A recent report by the US surgeon general suggested the need for more focus on smoking in low socioeconomic and other disparity groups. ${ }^{12}$ People in prisons are disadvantaged on a number of social and economic indicators that put them at risk for poor health outcomes ${ }^{13}{ }^{14}$ and are thus an important target population to reduce the harms of smoking. Prisons have several features that make them unique with regard to both the health effects of tobacco use and potential strategies to mitigate the risks. First, smoke exposure for people who smoke, as well as people who do not smoke, is likely to be more intense in prisons than in non-institutional settings. People in prisons live and work in confined indoor spaces that can be crowded and poorly ventilated. They also have limited movement options and restricted opportunities for outside air to avoid smoke exposure even if they do not smoke.

In 1993, a US Supreme Court ruling suggested that the exposure of prisoners to environmental smoke can be considered "cruel and unusual punishment" in violation of the Eighth Amendment. ${ }^{15}$ Since then, states have increasingly enacted various prison tobacco control policies. These include prohibiting smoking cigarettes (smoking bans) and/or all tobacco products, including smokeless tobacco (tobacco bans). These bans can be applied to indoor or outdoor environments, or both. ${ }^{16-18}$ England and Wales are also implementing or considering complete bans on smoking in prison. ${ }^{19}$ Unlike smoking restrictions in workplaces and restaurants outside institutions, complete smoking bans in prison restrict autonomy by preventing people from smoking anywhere, including living areas. Thus, we also determined whether state prison bans were associated with reductions in the rates of smoking related deaths, including from cancer, cardiovascular disease, and pulmonary disease. Given that smoking causes both immediate and longer term health effects, we also sought to understand whether the length of time a ban was in place was associated with greater reductions in mortality.

\section{Methods \\ Study design}

We first analyzed cross sectional survey data using the smoking attributable mortality, morbidity, and economic costs system and then conducted a population based time series analysis.

\section{Setting}

We included data from all US state prisons from 2001 to 2011. At year end 2006, midway through our observation period, the median length of time already served in prison was 21 months (interquartile range 7-64 months) and the median length of sentence was 84 months (42-180 months). Forty seven percent of sentences were 10 years or more. ${ }^{20}$ Nearly half of people released from prisons were in prison again by three years. ${ }^{21}$

\section{Data sources}

We used several sources of data for our analyses (table 1). $\Downarrow$ First, we obtained data on self reported smoking from the most recent cross sectional nationally representative survey of individuals in state prisons, the Bureau of Justice Statistics survey of inmates in state correctional facilities, 2004. Of 297 prisons selected by the Bureau of Justice Statistics for its survey, two refused and 12 were out of scope. Four reserve female prisons were added for a total of 287 participating state prisons, and 14499 individuals participated. ${ }^{22}$ Survey participants had been told verbally and in writing that participation was voluntary, answers were confidential, the purpose of the survey was statistical, and individuals would not be identified. ${ }^{22}$ The individual level data from this existing survey allowed us to calculate the prevalence of current, former, and never smoking in 2004. Using standard classifications, ${ }^{23}$ we coded never smokers as individuals who had never smoked at least 100 cigarettes in their lives. Current smokers had smoked at least 100 cigarettes in their lifetimes and smoked every day or some days at the time of the interview. Former smokers had ever smoked at least 100 cigarettes but did not smoke when interviewed. We also used age and sex from the survey of inmates in state correctional facilities to provide age (35-64 and $\geq 65$ ) and sex specific prevalence rates of the smoking statuses for our analyses on smoking attributable mortality and years of potential life lost. For descriptive purposes, we also examined responses to questions about use of smokeless tobacco (chewing tobacco and snuff).

Second, data on deaths (outcome of interest) from 2001 to 2011 and all 50 states was drawn from the Bureau of Justice Statistics deaths in custody reporting program, stratified by sex and age (35-39, 40-44, 45-49, 50-54, 60-64, 70-74, 75-79, 80-84, and $\geq 85$ ). These population based data did not include deaths in local (county) jails (collected in a separate Bureau of Justice Statistics program), federal prisons, or the District of Columbia. The Bureau of Justice Statistics has collected mortality data on people in state prisons for statistical analysis since 2001. State prisons report deaths among people in their custody, including deaths in private prisons, hospitals, or during transit. Cause of death is converted to ICD-10 (international classification of diseases, 10th revision) codes by a professional nosologist. In $66.2 \%$ of deaths from 2001 to 2011, an autopsy was performed. We examined deaths in 19 adult disease categories classified as related to smoking by the Centers for Disease Control and Prevention. ${ }^{25}$ We refer to all deaths within these disease categories as "smoking related" deaths. In sensitivity analyses, we also examined all other causes of death, referred to as "other causes."

Third, we obtained data from the Bureau of Justice Statistics national prisoner statistics program for year end state prison population estimates by sex and age group (denominator data).

Fourth, we collected data on tobacco control policies in the 50 states in each year from 2001 to 2011 (primary exposure of interest). We searched public websites about smoking policies and dates enacted, including Departments of Corrections websites, the American Nonsmokers' Rights Foundation, ${ }^{17}$ legislative websites, reports, ${ }^{26}$ and media reports. Inconsistencies between sources were resolved by favoring adopted legislation or official Department of Corrections' policies. Each state was categorized by type of ban and location (indoor/outdoor) in each year by using existing classifications. ${ }^{17}$ For instance, Arizona adopted an indoor smoke-free ban in $2007 .{ }^{27}$ Idaho had the most restrictive type of ban, which banned smoking and tobacco use indoor and outdoor from $1996 .^{28}$ If no data were available for a given ban category it was coded as missing.

Finally, to assess potential confounding, we collected data on the prevalence of smoking in adults in the general population outside prison of each state by year from the behavioral risk factor surveillance system. ${ }^{29} \mathrm{We}$ also obtained data from the Centers for Disease Control and Prevention's wide-ranging online data for epidemiologic research database for state, year, and sex specific estimates of deaths in the general population. 
We extrapolated available data (2001-10) to 2011 using Poisson regression.

\section{Statistical analyses \\ Smoking attributable mortality and years of potential life lost}

We used the smoking attributable mortality, morbidity, and economic costs system of the Centers for Disease Control and Prevention to calculate smoking attributable mortality, years of potential life lost, and the age adjusted smoking attributable mortality and years of potential life lost rates per 100000 population. ${ }^{25} \mathrm{We}$ entered smoking prevalence based on the individual level data from the survey of inmates in state correctional facilities, mortality data from the deaths in custody reporting program for individuals aged $\geq 35$, and prison populations from the national prisoner statistics program. The Centers for Disease Control and Prevention's smoking attributable mortality, morbidity, and economic costs system calculated smoking attributable mortality and years of potential life lost by multiplying the number of deaths from each of the 19 causes by estimates of the smoking attributable fraction of preventable deaths. The smoking attributable fraction estimates the public health burden of each risk factor and the relative importance of risk factors for multifactorial diseases. The external validity of smoking attributable mortality estimates with the smoking attributable mortality, morbidity, and economic costs system has previously been established. ${ }^{30}{ }^{31}$ For years of potential life lost, we used 2004 US population estimates of life expectancy. To compare to estimates of smoking attributable mortality and years of potential life lost for the US as whole (which includes deaths among people in prisons), we used the 2004 resident population and the 2004 smoking rates provided in the smoking attributable mortality, morbidity, and economic costs system, the most recent year for which these data are available.

\section{Sensitivity analysis for smoking attributable mortality and years of potential life lost}

Estimates from the smoking attributable mortality, morbidity, and economic costs system excluded deaths from burns and secondhand smoke, and this system does not provide confidence intervals. Further, the small numbers of individuals aged $\geq 65$ in the prison survey could result in imprecise estimates of smoking status. Thus, we used two age strata (rather than four) for our calculations and conducted sensitivity analyses that assigned inmates aged $\geq 65$ the same smoking prevalence as inmates aged 35-64 (assumption 2). In addition, given the presence of smoking bans in some prisons in 2004, survey estimates of current smoking were lower in prison than before arrest. We therefore also calculated smoking attributable mortality and years of potential life lost using estimates of current and former smoking before arrest for the age groups of 34-64 and $\geq 65$ (assumption 3).

\section{Association between smoking bans and smoking related deaths}

To assess the association between states implementing prison bans and smoking related deaths in prisons, we first calculated crude death rates for all smoking related causes of death by year and state, and then for mortality from smoking related cancers, cardiovascular diseases, and pulmonary diseases. States were selected as the unit of analysis as smoking bans are implemented at the state level. We estimated Poisson regression models $(\mathrm{n}=1100)$ to predict the number of deaths in each state $(i)$ and each year (j) between 2001 and 2011, with the number of inmates in each state and year serving as the exposure, and including separate dummy variables that indicated whether state $i$ in year $j$ had a smoking ban of a given type in place. All models included all ages and were adjusted for sex. We adjusted for calendar year to account for secular trends in mortality. We also adjusted for the prevalence of current smoking in the general population in each state and year to account for the potential confounding effect of state variation in smoking prevalence (outside prison).

We estimated a model for all smoking related deaths combined and then separate models for deaths from cancer, cardiovascular disease, and pulmonary disease. We expected differences in the association between bans and mortality based on the disease process. ${ }^{32}$ To assess whether the length of time a ban was in place was influential, subsequent models categorized time since implementation of bans with cut points at the 25 th centile $(0$ years), 50th centile (4 years), and 75 th centile (9 years) and adjusted for sex, calendar year, and state smoking rates. For instance, we expected a minimal time lag to affect mortality from cardiovascular diseases, such as ischemic heart disease, because tobacco can have immediate physiologic effects on platelet aggregation. ${ }^{32}$ Studies have also shown a reduction in acute myocardial infarction with the implementation of restaurant, bar, and workplace bans, without a change in the effect over time since the ban. ${ }^{33}$ Similarly, we expected both short and long term effects on pulmonary deaths, as smoking and smoke exposure can trigger an acute disease exacerbation and contribute to the development of chronic disease (such as chronic obstructive pulmonary disease). On the other hand, we expected that benefits on cancer mortality might become apparent over only a longer time period. ${ }^{34}$

\section{Sensitivity analysis for association between smoking bans and smoking related deaths}

We conducted sensitivity analyses adjusting for general population rates of all smoking related deaths, cancer, and cardiovascular and pulmonary diseases. In these models, we did not adjust for state smoking prevalence because of correlation between those variables. To determine if our results were also applicable to causes of death that have not been as strongly linked to smoking, we also modeled the association between tobacco and other causes of death, adjusting for state prevalence of smoking.

All analyses were conducted with Stata/SE 13.0 (College Station, TX).

\section{Results}

\section{Smoking attributable mortality and years of potential life lost}

About half (49.6\%) of people in state prisons at year end 2004 (unweighted $n=14499$; weighted $n=1226171$ ) were aged $\geq 35$, and 6.8\% (83 078) were women (table 2). $\Downarrow$ Among people of all ages in state prisons, $75.8 \%$ had ever smoked, $38.9 \%$ were current smokers, and $37.0 \%$ were former smokers. More than half $(56 \%)$ reported smoking daily before their arrest, with another $7.6 \%$ reporting smoking some days before arrest. The prevalence of current (former) smoking among people aged $35-64$ and $\geq 65$ was $38.5 \%$ (39.6\%) and $17.7 \%$ (48.2\%), respectively, for men and $46.7 \%$ (33.6\%) and 5.9\% (38.0\%), respectively, for women. Compared with smoking, a much smaller proportion had ever used smokeless forms of tobacco $(22.4 \%)$ or currently used them (1.9\% used every day and $2.5 \%$ used some days). 
In all age groups of people in state prisons in 2001-11, there were 16024 deaths attributable to the 19 smoking related causes of death (table 3). $\Downarrow$ Of these, $15289(95.4 \%)$ were among individuals aged $\geq 35 ; 44.6 \%(n=7152)$ of which attributable to smoking. At the time of death, the mean age was $56.6(\mathrm{SD}=12.8)$ and the median length of incarceration was 6.1 years (interquartile range 1.8-14.7 years). Of smoking attributable deaths, 237 (3.3\%) were among women. The largest categories of these deaths were tracheal, lung, and bronchial cancer (smoking attributable mortality $n=2573$ ), ischemic heart disease $(\mathrm{n}=1554)$, other heart disease $(\mathrm{n}=1213)$, cerebrovascular disease $(n=359)$, chronic obstructive pulmonary disease $(n=288)$, and pneumonia/influenza $(\mathrm{n}=174)$.

In 2001-11, the age adjusted rate of smoking attributable mortality was 360 per 100000 . The number of age adjusted years of potential life lost was 5149 per 100000 (table 4, assumption 1). $\Downarrow$ In sensitivity analyses that either assumed a constant prevalence of smoking for individuals $\geq 35$ (assumption 2 ) or used the pre-arrest prevalence of smoking (assumption 3), the age adjusted smoking attributable mortality and years of potential life lost rates were increased compared with analyses that used prison smoking prevalences for age groups 34-64 and $\geq 65$ (assumption 1) (for assumption 2 the smoking attributable mortality rate was 411 per 100000 and years of potential life lost rate 5667 per 100000 ; for assumption 3 the smoking-attributable mortality rate was 418 per 100000 and years of potential life lost rate 5924 per 100000 , respectively). For the US population as a whole in 2004, the smoking attributable mortality rate was 248 per 100000 and the years of potential life lost was 3501 per 100000 .

\section{Association between smoking bans and smoking related deaths}

In 2001, half of all states had any smoking ban ( $n=25$; table A, appendix 1). By 2011, 48 states had implemented a ban on smoking in prisons. All states with a ban had a ban on smoking indoors. By 2011, 44 states banned tobacco indoors and 39 states banned smoking or tobacco outdoors. Crude mortality rates in states in years with any ban were lower than in those without a ban (incidence rate ratio 0.86 (110.4/128.9), 95\% confidence interval 0.83 to 0.89 ; figure). $\downarrow$ States with the most restrictive bans (outdoor and indoor bans) had the lowest mortality rates (incidence rate ratio $0.85,95 \%$ confidence interval $0.82,0.87$ ).

Adjustment for sex, calendar year, and smoking prevalence in the general population in the state (table 5, model 1), $\downarrow$ any ban was associated with a reduced incidence of any smoking related death (adjusted incidence rate ratio $0.91,0.88$ to 0.95 ), including significant reductions in cardiovascular deaths $(0.91,0.87$ to $0.96)$ and pulmonary deaths $(0.71,0.61$ to 0.82$)$. Men had significantly higher rates of death than women for all smoking related causes, cancer, and cardiovascular disease. In categorical analyses (table 5, model 2), $\Downarrow$ bans in place for more than nine years were associated with reductions in all smoking related deaths $(0.89,0.85$ to 0.94$)$, cancer deaths $(0.81,0.74$ to 0.90$)$, and pulmonary deaths $(0.66,0.54$ to 0.80$)$ compared with places with no ban.

In sensitivity analyses, we adjusted for rates of death from smoking related causes in the general population by state and found little substantive change in the point estimates, although the $95 \%$ confidence intervals were marginally wider (table B, appendix 1). To further confirm the robustness of our results, we examined deaths from causes other than tobacco from 2001-11 (table C, appendix 1). No similar reductions in mortality were associated with smoking bans for deaths from other causes (adjusted incidence rate ratio 1.05, 95\% confidence interval 1.00 to 1.09 ; appendix 2).

\section{Discussion Main findings}

Smoking contributes to substantial excess mortality in prisons. Our study suggests that the implementation of smoking bans in prison is associated with reductions in smoking related mortality among people in prisons, particularly cardiovascular and pulmonary deaths. These findings are likely related to reductions in smoking and exposure to secondhand smoke among people in prisons. Bans in place for nine or more years were also associated with reduced cancer mortality.

\section{Strengths and weaknesses of study}

We might have underestimated smoking attributable mortality for several reasons. ${ }^{12}$ First, people who do not smoke might experience a higher intensity of secondhand exposure in cells and indoor prison spaces with poor ventilation. The smoking attributable mortality, morbidity, and economic costs system does not include effects of secondhand smoke in its calculations of smoking attributable mortality. Second, in prisons, people who smoke might smoke more than other populations; thus, the relative risk assumptions used in the system software to calculate smoking attributable mortality might be inappropriately low for this population. Third, in addition to the 19 causes of death thought to be related to smoking in prior reports of smoking attributable mortality in the general populations, ${ }^{25}$ additional causes of death might be related to smoking, such as colon cancer. ${ }^{12}$ These were not accounted for in the system software we used. Fourth, the smoking attributable mortality, morbidity, and economic costs system does not account for pipe or cigar smoking. In addition, our estimates of smoking attributable mortality and years of potential life lost were limited by the small number of older people in the prison survey. Our estimates of smoking in older people might be unstable, although the decline in smoking prevalence among such people observed mirrors the trend in the general population.

Our analysis of the effects of tobacco control polices on mortality was based on the best available observational data to examine this question. A randomized trial of these policies that is adequately long and of sufficient size to assess mortality outcomes is unlikely to be conducted. Our data do not include deaths in local jails or federal prisons, among individuals on probation or parole, or among people released from prison. Some individuals with major illness could have been released from prison on medical parole or compassionate release before dying from cancer or other illnesses. Our data did not capture these deaths. Underlying cause of death was determined by state prisons systems and Bureau of Justice Statistics by using algorithms that do not necessarily correspond to algorithms used by the Centers for Disease Control and Prevention to classify cause of death when multiple causes contribute.

Our findings on the association between smoking bans and mortality also have limitations. First, as noted by the Institute of Medicine, it can be difficult to separate the direct effects of a ban from dissemination of information about the ban, associated education about secondhand smoke, and associated efforts at smoking cessation. ${ }^{35}$ Second, states that implemented prison bans might also have implemented other workplace or public bans, which reduced smoking related mortality. Our sensitivity analyses, however, suggest that our results are robust. Third, because of limitations of our data we could not adjust 
for differences in the distribution of age across states. The mortality reductions we observed could have occurred as a result of reductions in smoking or exposure to secondhand smoke, or both. Finally, our estimates of the effects of time since the implementation of bans might have been conservative as people might not have been exposed to the bans for the whole time, given transitions in and out of prison.

\section{Strengths and weaknesses in relation to other studies}

The association between smoking bans in prison and mortality has not been previously reported. In the population outside prison, smoke-free legislation has been associated with reduced admission to hospital and mortality from coronary events, other heart disease, cerebrovascular disease, and respiratory disease..$^{33}$ More comprehensive laws have been associated with greater risk reductions. ${ }^{33}$ The Institute of Medicine also suggested that reduced exposure to secondhand smoke from smoking bans led to declines in myocardial infarction. ${ }^{35}$ Other studies of workplace and public smoking bans have shown a reduction in visits to emergency departments and hospital admissions for smoking related diseases after implementation. ${ }^{36} 37$ To our knowledge, this is the first study to show an association between smoking bans and reduced cancer mortality over time. The long latency between smoking exposure and the development of cancer might make this association more challenging to demonstrate through epidemiologic studies in populations outside prison that are more mobile and might experience a lower intensity of exposure to smoke than people in prisons. Fry and colleagues noted, however, that compared with people who continue to smoke, those who quit smoking have half the risk of lung cancer 10 years after they quit smoking ${ }^{34}$ — a finding that is consistent with our results. Previous research, however, has not documented the effect of smoking bans on cancer mortality; this finding should therefore be replicated in other settings.

\section{Meaning of the study}

Our results suggest that smoking bans in prisons can reduce the risk of death in prison. Smoking bans do not directly reduce mortality but act through effects on smoking and exposure to secondhand smoke. The institution of prison smoking bans has been associated with a reduction in exposure to secondhand smoke and improvements in air quality. ${ }^{16}{ }^{38}$ Smoking bans can also reduce the initiation of smoking in prison, improve health among correctional officers and other prison staff, improve fire safety, and reduce costs associated with liability insurance, facility maintenance, and healthcare. ${ }^{7}$

On the other hand, complete (indoor and outdoor) smoking and tobacco bans in prisons strongly limit individual autonomy and might not prepare individuals with tobacco use disorders for life in the community, where they can purchase and consume tobacco. Internationally, various types of incomplete bans are being implemented, such as bans that prohibit smoking in public prison spaces, in cells, or in all spaces except for designated smoking areas. Some prisons have also prohibited correctional facilities from forcing people who do not smoke to share cells with inmates who smoke. ${ }^{19}{ }^{39}$ In addition, smoking bans do not lead to sustained long term cessation. Many people resume smoking after release from prison, ${ }^{7}$ and others might be transferred to or re-incarcerated in jails, halfway houses, and drug treatment facilities without bans. Finally, some inmates smoke despite bans, ${ }^{18}$ which can lead to correctional sanctions and negative health outcomes for people with tobacco use disorders. Reduced smoking and smoke exposure, however, can have positive health benefits even if there is not complete adherence with a ban.

Pharmacologically supported tobacco cessation treatment and behavioral interventions are important adjuncts for tobacco use disorders and need wider dissemination in prisons. ${ }^{40}$ Prevention of relapse during the transition back to the community is also critical. People with mental health and substance use disorders, which are associated with tobacco use,,$^{42}$ might require specialized interventions to help maintain long term cessation and manage forced abstinence in prison. Smoking cessation can lead to secondary health benefits in children and families after individuals are released from prison. Other healthcare services that can provide benefit to people with a history of smoking include vaccination against influenza and pneumococcal disease, evidence based management of chronic obstructive pulmonary disease, and primary and secondary prevention of heart and cerebrovascular disease.

\section{Unanswered questions and future research}

Further research is needed on several related issues, such as the effect of tobacco policies among correctional officers and prison staff, who also smoke at disproportionately high rates ${ }^{42}$; public expenditures because of smoking related illness in prisons and after release; the costs of tobacco control and cessation interventions in prisons; whether incarceration in correctional facilities that permit smoking increase smoking initiation or consumption; when maximal effects on cancer mortality are observed (including after release from prison); and the use of smokeless and electronic cigarettes in prisons. We noted an overall increase in the 2011 mortality rate, a finding that needs further investigation if it represents a trend. Whereas death rates in prisons are often similar to or slightly lower than those in the general population, for the same age, sex, and race (in part because of protection from deaths from injury), the risk of death increases after release from prison. Lung cancer and cardiovascular mortality are important contributors to death after release from prison. ${ }^{11}$ Prison smoking bans could reduce mortality after release. While we observed significant benefits of smoking bans on mortality, ongoing research and implementation efforts are needed to promote effective long term cessation in prisons and after release as part of a comprehensive tobacco strategy for this high risk group.

We thank Marc F Stern and Karen Cropsey for their valuable input into this study.

Preliminary data from portions of this study were presented at the Society for General Internal Medicine 36th Annual Meeting in Denver, CO, on 24 April 2013 and at the 6th Academic and Health Policy Conference on Correctional Health, Chicago, IL, on 21 March 2013.

Contributions: IAB, EAC, and WJS designed the study. IAB wrote the protocol and supervised data collection and analysis. EAC and WJS participated in data collection, data interpretation, and revisions of the manuscript. JFS and PMK participated in data interpretation and revising the manuscript. IAB and SRM conducted literature searches, and SRM coordinated data collection and approvals. IAB and PMK undertook the statistical analysis. IAB wrote the first draft of the manuscript. All authors contributed to and have approved the final manuscript. All authors had full access to all the data in the study and take responsibility for the integrity of the data and the accuracy of the data analysis. IAB is guarantor.

Funding: This study was supported by the Bureau of Justice Statistics Visiting Fellows Program, US Department of Justice (grant No 2011-BJ-CX-K073). The views and opinions expressed do not 


\section{What is already known on this topic}

People in prisons represent a large and high disparity population with a high prevalence of tobacco use

Prisons have increasingly implemented prison smoking and tobacco bans, but the effects of smoking on mortality and health benefit of these policies have not been evaluated

\section{What this paper adds}

Our national study provides estimates of the rates of smoking attributable mortality and years of potential life lost in prisons, which are higher than in the general population

Prison smoking bans are associated with reductions in mortality from smoking related causes

necessarily represent the views and opinion of the Bureau of Justice Statistics or the US Department of Justice.

Competing interests: All authors have completed the ICMJE uniform disclosure form at www.icmje.org/coi_disclosure.pdf and declare: no support from any organization for the submitted work; no financial relationships with any organizations that might have an interest in the submitted work in the previous three years; no other relationships or activities that could appear to have influenced the submitted work.

Ethical approval: This study was approved by the Colorado Multiple Institutional Review Board (protocol 12-0092).

Data sharing: Bureau of Justice Statistics data are archived at the National Archive of Criminal Justice Data for public download and use (NACJD; www.icpsr.umich.edu/icpsrweb/NACJD/). Due to the sensitive nature and individual level records of the Deaths in Custody Reporting Program (Deaths in Custody Reporting Program; ICPSR 34277), this collection has been judged by a disclosure review panel to be restricted and must be used in an enclave setting. Due to the individual level records of the National Corrections Reporting Program (NCRP; ICPSR 34984), this collection has been judged by a disclosure review panel to be restricted, but the data can be downloaded to computers outside of an enclave setting by application to NACJD. Data from the National Prisoners Statistics Program (National Prisoner Statistics program; ICPSR 34540) are freely available to the public.

Transparency declaration: The lead author affirms that this manuscript is an honest, accurate, and transparent account of the study being reported; that no important aspects of the study have been omitted; and that any discrepancies from the study as planned have been explained.

1 World Health Organization. Tobacco fact sheet. WHO, 2013.

2 Carson EA, Sabol WJ. Prisoners in 2011. US Department of Justice, Bureau of Justice Statistics, 2012.

3 Singleton N, Farrell M, Meltzer H. Substance misuse among prisoners in England and Wales. Int Rev Psychiatry 2003:15:150-2.

4 Awofeso N, Testaz R, Wyper S, Morris S. Smoking prevalence in New South Wales correctional facilities, 2000. Tob Control 2001;10:84-5.

5 Baker A, Ivers RG, Bowman J, Butler T, Kay-Lambkin FJ, Wye P, et al. Where there's smoke, there's fire: high prevalence of smoking among some sub-populations and recommendations for intervention. Drug Alcohol Rev 2006;25:85-96.

6 Belcher JM, Butler T, Richmond RL, Wodak AD, Wilhelm K. Smoking and its correlates in an Australian prisoner population. Drug Alcohol Rev 2006;25:343-8.

7 Lincoln T, Tuthill RW, Roberts CA, Kennedy S, Hammett TM, Langmore-Avila E, et al. Resumption of smoking after release from a tobacco-free correctional facility. $J$ Correct Health Care 2009;15:190-6.

8 Cropsey KL, Eldridge GD, Weaver MF, Villalobos GC, Stitzer ML. Expired carbon monoxide levels in self-reported smokers and nonsmokers in prison. Nicotine Tob Res 2006:8:653-9.

9 Binswanger IA, Krueger PM, Steiner JF. Prevalence of chronic medical conditions among jail and prison inmates in the USA compared with the general population. J Epidemiol Community Health 2009;63:912-9.

10 Binswanger IA, Blatchford PJ, Mueller SR, Stern MF. Mortality after prison release: opioid overdose and other causes of death, risk factors, and time trends from 1999 to 2009. An Intern Med 2013:159:592-600.

11 Binswanger IA, Stern MF, Deyo RA, Heagerty PJ, Cheadle A, Elmore JG, et al. Release from prison—a high risk of death for former inmates. N Engl J Med 2007;356:157-65.

12 US Department of Health and Human Services. The health consequences of smoking - 50 years of progress: a report of the surgeon general. Centers for Disease Control and Prevention, National Center for Chronic Disease Prevention and Health Promotion, Office on Smoking and Health, 2014.

13 Massoglia M. Incarceration, health, and racial disparities in health. Law Soc Rev 2008;42:275-306

14 Binswanger IA, Redmond N, Steiner JF, Hicks LS. Health disparities and the criminal justice system: an agenda for further research and action. J Urban Health 2012;89:98-107.

15 Helling $v$ Mckinney; US Supreme Court, 1993.
16 Proescholdbell SK, Foley KL, Johnson J, Malek SH. Indoor air quality in prisons before and after implementation of a smoking ban law. Tob Control 2008;17:123-7.

17 American Nonsmokers' Rights Foundation. $100 \%$ smokefree correctional facilities. American Nonsmokers' Rights Foundation, 2012.

18 Cropsey KL, Kristeller JL. The effects of a prison smoking ban on smoking behavior and withdrawal symptoms. Addict Behav 2005;30:589-94.

19 Smoking ban considered for prisons. BBC News September 20, 2013.

20 US Department of Justice, Office of Justice Programs, Bureau of Justice Statistics. National corrections reporting program, 2006, Icpsr30641.V1. Inter-university Consortium for Political and Social Research, 2012

21 Durose MR, Cooper AD, Snyder HN. Recidivism of prisoners released in 30 states in 2005: patterns from 2005 to 2010. Bureau of Justice Statistics, 2014.

22 Inter-university Consortium for Political and Social Research. Survey of Inmates in State and Federal Correctional Facilities, 2004, US Department of Justice, Bureau of Justice Statistics, Codebook. Inter-university Consortium for Political and Social Research, 2007.

23 Centers for Disease Control and Prevention. State-specific secondhand smoke exposure and current cigarette smoking among adults-United States, 2008. JAMA 2009;302:2654-56.

24 Bondy SJ, Victor JC, Diemert LM. Origin and use of the 100 cigarette criterion in tobacco surveys. Tob Control 2009;18:317-23.

25 Centers for Disease Control and Prevention. Smoking-attributable mortality, years of potential life lost, and productivity losses_-United States, 2000-2004. MMWR Morb Mortal Wkly Rep 2008;57:1226-8.

26 Cork K. Tobacco behind bars: policy options for the adult correctional population. Public Health Law Center, 2012

27 Arizona Department of Corrections. Smoking and tobacco regulations. 100; DO 109, 17 April 2007.

28 Idaho Department of Corrections. Tobacco free environment. Policy No 104. 1 Novembe 1996.

29 Center for Disease Control and Prevention (CDC). Behavioral risk factor surveillance system survey data. CDC, 2001-11.

30 McAnulty JM, Hopkins DD, Grant-Worley JA, Baron RC, Fleming DW. A comparison of alternative systems for measuring smoking-attributable deaths in Oregon, USA. Tob Control 1994;3:115.

31 Thomas AR, Hedberg K, Fleming DW. Comparison of physician based reporting of tobacco attributable deaths and computer derived estimates of smoking attributable deaths, Oregon, 1989 to 1996 . Tob Control 2001;10:161-4.

32 Law MR, Morris JK, Wald NJ. Environmental tobacco smoke exposure and ischaemic heart disease: an evaluation of the evidence. BMJ 1997;315:973-80.

33 Tan CE, Glantz SA. Association between smoke-free legislation and hospitalizations for cardiac, cerebrovascular, and respiratory diseases: a meta-analysis. Circulation 2012;126:2177-83.

34 Fry JS, Lee PN, Forey BA, Coombs KJ. How rapidly does the excess risk of lung cance decline following quitting smoking? A quantitative review using the negative exponential model. Regul Toxicol Pharmacol 2013;67:13-26.

35 Institute of Medicine. Secondhand smoke exposure and cardiovascular effects: making sense of the evidence. loM, 2009.

36 Khuder SA, Milz S, Jordan T, Price J, Silvestri K, Butler P. The impact of a smoking ban on hospital admissions for coronary heart disease. Prev Med 2007:45:3-8.

37 State of North Carolina. The North Carolina smoke free restaurants and bars law and emergency department admissions for acute myocardial infarction. Department of Health and Human Services, DoPH, 2011.

38 Ritter C, Huynh CK, Etter JF, Elger BS. Exposure to tobacco smoke before and after a partial smoking ban in prison: indoors air quality measures. Tob Control 2011;21:488-91.

39 Dorsett J. Queensland announces plans to ban smoking in all jails from May 2014. ABC News , 4 November 2013.

40 Clarke JG, Stein LA, Martin RA, Martin SA, Parker D, Lopes CE, et al. Forced smoking abstinence: not enough for smoking cessation. JAMA Intern Med 2013;173:789-94.

41 Cropsey K, Eldridge G, Weaver M, Villalobos G, Stitzer M, Best A. Smoking cessation intervention for female prisoners: addressing an urgent public health need. Am J Public Health 2008:98:1894-901.

42 Butler T, Richmond R, Belcher J, Wilhelm K, Wodak A. Should smoking be banned in prisons? Tob Control 2007;16:291-3.

\section{Accepted: 07 July 2014}

\section{Cite this as: BMJ 2014;349:g4542}

This is an Open Access article distributed in accordance with the Creative Commons Attribution Non Commercial (CC BY-NC 3.0) license, which permits others to distribute, remix, adapt, build upon this work non-commercially, and license their derivative works on different terms, provided the original work is properly cited and the use is non-commercial. See: http://creativecommons.org/licenses/by-nc/3.0/. 


\section{Tables}

Table 1/ Sources of data on prison tobacco control policies and deaths from smoking in United States

\begin{tabular}{|c|c|c|c|}
\hline Data source & Year(s) & Agency & Data elements used \\
\hline Survey of inmates in state correctional facilities & 2004 & Bureau of Justice Statistics & $\begin{array}{l}\text { Smoking and tobacco use data for smoking attributable } \\
\text { mortality/years of potential life lost analysis and descriptive } \\
\text { purposes }\end{array}$ \\
\hline Deaths in custody reporting program & $2001-11$ & Bureau of Justice Statistics & $\begin{array}{l}\text { Number of deaths and cause of death among prison inmates } \\
\text { (primary outcome) }\end{array}$ \\
\hline National prisoner statistics program & $2001-11$ & Bureau of Justice Statistics & Prison population numbers (denominator) \\
\hline $\begin{array}{l}\text { Smoking attributable mortality, morbidity, and } \\
\text { economic costs }\end{array}$ & $2001-11$ & $\begin{array}{l}\text { Centers for Disease Control and } \\
\text { Prevention }\end{array}$ & Smoking attributable mortality and years of potential life lost \\
\hline $\begin{array}{l}\text { Departments of Corrections websites, American } \\
\text { Nonsmokers' Rights Foundation, legislative websites, } \\
\text { reports, and media reports }\end{array}$ & $2001-11$ & Various & $\begin{array}{l}\text { Tobacco control policies in each state correctional } \\
\text { department (exposure) }\end{array}$ \\
\hline Behavioral risk factor surveillance system & $2001-11$ & $\begin{array}{l}\text { Centers for Disease Control and } \\
\text { Prevention }\end{array}$ & $\begin{array}{l}\text { State general population smoking prevalence for adjustment } \\
\text { purposes }\end{array}$ \\
\hline Wide-ranging online data for epidemiologic research & $2001-11$ & $\begin{array}{l}\text { Centers for Disease Control and } \\
\text { Prevention }\end{array}$ & $\begin{array}{l}\text { State general population death rates for ages } 15-64 \text { by cause } \\
\text { for sensitivity analyses }\end{array}$ \\
\hline
\end{tabular}


Table 2/ Weighted national prevalence of smoking and tobacco use among people of all ages in state prisons in 2004 ( $n=14$ 499, weighted $\mathrm{n}=1226$ 171). Figures are numbers (percentage) of people in prisons

\begin{tabular}{|c|c|c|c|}
\hline & All people in prisons & Men & Women \\
\hline Total & 1226171 & $1143093(93.2)$ & $83078(6.8)$ \\
\hline \multicolumn{4}{|l|}{ Age (years): } \\
\hline$<35$ & $618355(50.4)$ & $580932(50.8)$ & $37424(45.1)$ \\
\hline $35-64$ & $598305(48.8)$ & $552880(48.4)$ & $45425(54.7)$ \\
\hline$\geq 64$ & $11688(1.0)$ & $11416(1.0)$ & $272(0.3)$ \\
\hline \multicolumn{4}{|l|}{ Race/ethnicity: } \\
\hline African American* & $496936(40.5)$ & $468998(41.0)$ & $27936(33.6)$ \\
\hline White* & $431482(35.2)$ & $394013(34.5)$ & $37469(45.1)$ \\
\hline Hispanic & $222694(18.2)$ & $210941(18.4)$ & $11753(14.1)$ \\
\hline American Indian/Alaska Native* & $20696(1.7)$ & $18680(1.6)$ & $2015(2.4)$ \\
\hline Asian/Pacific Islander* & $13080(1.1)$ & $12829(1.1)$ & $250(0.3)$ \\
\hline Other/missing & $41284(3.4)$ & $37628(3.2)$ & $3655(4.4)$ \\
\hline Ever smoked at least 100 cigarettes & $919054(75.8)$ & $854672(75.6)$ & $64382(78.8)$ \\
\hline \multicolumn{4}{|l|}{ Smoking status: } \\
\hline Current & $470925(38.9)$ & 432778 (38.3) & $38147(46.7)$ \\
\hline Former & $448129(37.0)$ & $421894(37.3)$ & $26235(32.1)$ \\
\hline Never† & $293120(24.2)$ & $275759(24.4)$ & $17362(21.2)$ \\
\hline \multicolumn{4}{|l|}{ Smoking before arrest: } \\
\hline Every day & $690280(56.3)$ & $637144(55.8)$ & $53136(64.0)$ \\
\hline Some days & $92954(7.6)$ & $88185(7.7)$ & $4769(7.7)$ \\
\hline Not at all & $441943(36.1)$ & $416805(36.5)$ & $25138(36.5)$ \\
\hline Ever used chewing tobacco or snuff & $271782(22.4)$ & $266137(23.5)$ & $5599(6.8)$ \\
\hline \multicolumn{4}{|l|}{ Uses chewing tobacco or snuff: } \\
\hline Every day & $23561(1.9)$ & $23433(2.1)$ & $128(0.2)$ \\
\hline Some days & $30300(2.5)$ & $30018(2.6)$ & $281(0.3)$ \\
\hline Not at all & $1172216(95.6)$ & 1089547 (95.3) & $82669(99.5)$ \\
\hline
\end{tabular}

*Not of Hispanic origin.

$\dagger$ Never smokers are defined as individuals who never smoked 100 cigarettes in their lives. 
Table 3| Deaths in categories of smoking related cause of death and smoking attributable mortality among people in prisons, 2001-11

\begin{tabular}{|c|c|c|c|c|c|c|c|c|c|}
\hline \multirow[b]{3}{*}{ Cause of death } & \multicolumn{6}{|c|}{ Deaths } & \multirow{2}{*}{\multicolumn{3}{|c|}{ Smoking attributable mortality }} \\
\hline & \multicolumn{3}{|c|}{ All ages } & \multicolumn{3}{|c|}{ Age $\geq 35$} & & & \\
\hline & Men & Women & Overall & Men & Women & Overall & Men & Women & Overall \\
\hline \multicolumn{10}{|l|}{ Malignant neoplasm: } \\
\hline Lip, oral cavity, pharynx & 216 & 3 & 219 & 213 & 3 & 216 & 172 & 2 & 174 \\
\hline Esophagus & 217 & 4 & 221 & 217 & 4 & 221 & 167 & 4 & 171 \\
\hline Stomach & 207 & 4 & 211 & 195 & 3 & 198 & 67 & 0 & 67 \\
\hline Pancreas & 438 & 14 & 452 & 431 & 14 & 445 & 144 & 4 & 148 \\
\hline Larynx & 95 & 4 & 99 & 95 & 4 & 99 & 82 & 4 & 86 \\
\hline Trachea/lung/bronchus & 2748 & 100 & 2849 & 2733 & 100 & 2833 & 2488 & 85 & 2573 \\
\hline Cervix uteri & 0 & 12 & 12 & 0 & 10 & 10 & 0 & 1 & 1 \\
\hline Kidney and renal pelvis & 201 & 4 & 205 & 193 & 3 & 196 & 90 & 0 & 90 \\
\hline Urinary bladder & 152 & 1 & 153 & 152 & 1 & 153 & 82 & 0 & 82 \\
\hline Acute myeloid leukemia & 85 & 4 & 89 & 71 & 4 & 75 & 21 & 0 & 21 \\
\hline Total cancer & 4339 & 151 & 4510 & 4300 & 146 & 4446 & 3313 & 100 & 3413 \\
\hline \multicolumn{10}{|l|}{ Cardiovascular disease (CVD): } \\
\hline Ischemic heart & 3959 & 105 & 4064 & 3836 & 105 & 3941 & 1507 & 47 & 1554 \\
\hline Other heart & 4993 & 199 & 5192 & 4614 & 167 & 4781 & 1181 & 32 & 1213 \\
\hline Cerebrovascular & 928 & 57 & 985 & 862 & 53 & 915 & 333 & 26 & 359 \\
\hline Atherosclerosis & 32 & 2 & 34 & 31 & 2 & 33 & 10 & 0 & 10 \\
\hline Aortic aneurysm & 122 & 3 & 125 & 117 & 2 & 119 & 82 & 1 & 83 \\
\hline Other circulatory & 50 & 4 & 54 & 45 & 4 & 49 & 11 & 0 & 11 \\
\hline Total CVD & 10084 & 370 & 10454 & 9505 & 333 & 9838 & 3124 & 106 & 3230 \\
\hline \multicolumn{10}{|l|}{ Respiratory diseases: } \\
\hline Pneumonia/influenza & 612 & 52 & 664 & 565 & 48 & 613 & 158 & 16 & 174 \\
\hline Bronchitis/emphysema & 49 & 2 & 51 & 47 & 2 & 49 & 45 & 2 & 47 \\
\hline Other chronic obstructive pulmonary disease $\dagger$ & 331 & 14 & 345 & 329 & 14 & 343 & 275 & 13 & 288 \\
\hline Total respiratory & 992 & 68 & 1060 & 941 & 64 & 1005 & 478 & 31 & 509 \\
\hline Overall total & 15435 & 589 & 16024 & 14746 & 543 & 15289 & 6915 & 237 & 7152 \\
\hline
\end{tabular}

${ }^{*}$ Calculated only for people aged $\geq 35$.

†ICD-10 code J44. 
Table 4| Annual smoking attributable mortality and years of potential life lost in US state prisons (2001-11) under varying assumptions and in US general population (2004)

\section{US state prisons (2001-11)}

Assumption $1^{\star}$ Assumption 2† Assumption 3‡

US general population (2004)

Smoking attributable mortality 7152

7424 8120 379727

Smoking attributable mortality rate/100 000

$360 \quad 411 \quad 418$

248

Number of years of potential life lost

170191

173202

192826

5392848

Years of potential life lost/100 000

$\begin{array}{lll}5149 & 5667 & 5924\end{array}$

3501

*Uses current in prison smoking for prisoners aged 35-65 and $\geq 65$.

†Uses current in prison smoking for prisoners aged $\geq 35$.

fUses current smoking before arrest for prisoners aged $35-65$ and $\geq 65$. 
Table 5| Association between any state prison smoking ban and smoking related deaths adjusted for sex, calendar year, and state smoking prevalence in general population (model 1) and between year since ban and smoking related deaths adjusted for sex, calendar year, and state general population smoking prevalence (model 2). Figures are adjusted incidence rate ratios (95\% confidence interval)

\begin{tabular}{|c|c|c|c|c|}
\hline & \multicolumn{4}{|c|}{ Smoking related cause of death } \\
\hline & All categories & Cancer & Cardiovascular & Pulmonary \\
\hline \multicolumn{5}{|l|}{ Model 1: any smoking ban } \\
\hline Any ban & 0.91 (0.88 to 0.95$)$ & $0.96(0.89$ to 1.03$)$ & 0.91 (0.87 to 0.96$)$ & 0.71 (0.61 to 0.82$)$ \\
\hline Calendar year & $1.04(1.03$ to 1.04$)$ & $1.06(1.05$ to 1.07$)$ & 1.02 (1.01 to 1.03$)$ & 1.05 (1.04 to 1.08$)$ \\
\hline Men & 1.96 (1.80 to 2.12$)$ & $2.16(1.84$ to 2.54$)$ & 2.03 (1.83 to 2.25$)$ & 1.08 (0.84 to 1.39$)$ \\
\hline State population prevalence of smoking & $1.05(1.05$ to 1.07$)$ & $1.06(1.05$ to 1.07$)$ & $1.06(1.05$ to 1.07$)$ & $1.02(1.00$ to 1.04$)$ \\
\hline \multicolumn{5}{|c|}{ Model 2: years since smoking ban implemented } \\
\hline \multicolumn{5}{|l|}{ Years since ban: } \\
\hline 0 & Reference & Reference & Reference & Reference \\
\hline$>0-<4$ & $0.96(0.92$ to 1.01$)$ & $0.96(0.88$ to 1.05$)$ & $0.99(0.93$ to 1.04$)$ & $0.74(0.62$ to 0.88$)$ \\
\hline$\geq 4-<9$ & $0.93(0.89$ to 0.97$)$ & $0.94(0.86$ to 1.02$)$ & 0.93 (0.88 to 0.98$)$ & $0.83(0.70$ to 0.99$)$ \\
\hline$\geq 9$ & $0.89(0.85$ to 0.94$)$ & $0.81(0.74$ to 0.90$)$ & 0.95 (0.89 to 1.02$)$ & 0.66 (0.54 to 0.80$)$ \\
\hline Calendar year & 1.04 (1.03 to 1.04$)$ & 1.07 (1.06 to 1.08$)$ & 1.02 (1.01 to 1.03 ) & 1.07 (1.04 to 1.09$)$ \\
\hline Men & 1.95 (1.80 to 2.12$)$ & 2.15 (1.83 to 2.53 ) & 2.03 (1.83 to 2.26$)$ & 1.08 (0.84 to 1.38$)$ \\
\hline State prevalence of smoking & $1.06(1.06$ to 1.07$)$ & 1.06 (1.05 to 1.07$)$ & 1.07 (1.06 to 1.07$)$ & 1.02 (1.01 to 1.04$)$ \\
\hline
\end{tabular}




\section{Figure}

- General population aged 25-64

- - - Prisons without ban

--.-- Prisons with any ban

-- Prisons with tobacco ban indoors

- - Prisons with tobacco and smoking ban outdoors

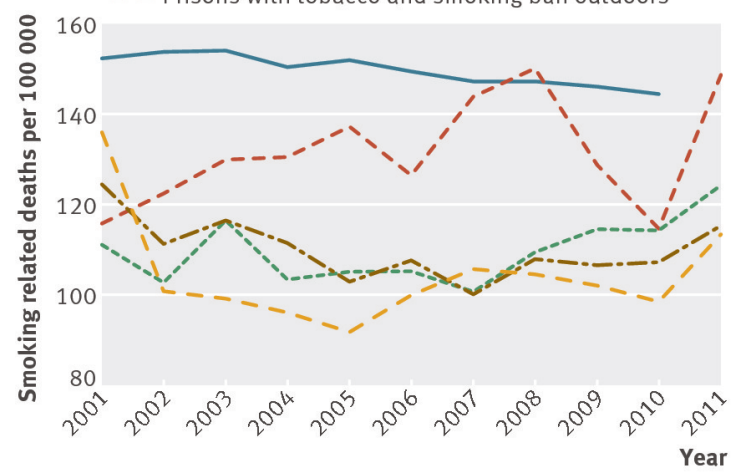

Crude smoking related mortality rates (deaths per 100 000) in prisons in states with and without smoking bans and in general (non-prison) population by year. Categories of bans are not mutually exclusive 